\title{
Persistence of dry matter yield among New Zealand perennial ryegrass (Lolium perenne L.) cultivars: insights from a long-term data set
}

\author{
D.F. CHAPMAN ${ }^{1}$, P.D. MUIR ${ }^{2}$ and M.J. FAVILLE ${ }^{3}$ \\ ${ }^{1}$ DairyNZ, P.O. Box 160, Lincoln University, Lincoln 7647 \\ ${ }^{2}$ On Farm Research, P.O. Box 1142, Hastings 4156 \\ ${ }^{3}$ AgResearch Grasslands, Private Bag 11008, Palmerston North 4442
}

david.chapman@dairynz.co.nz

\begin{abstract}
Persistence of herbage yield is an important productivity trait of grass species and cultivars in New Zealand pastures. However, relatively little is known about genetic variation in this trait, principally because few studies comparing yield have continued beyond 3 years. This paper reports results from a comparison of 25 perennial ryegrass cultivars representing a wide range of functional types and genetic backgrounds conducted under sheep grazing in a summer-dry environment. Dry matter (DM) yield was measured for the first 3 years after sowing, then again in years seven and eight post-sowing, and in year ten post-sowing. Endophyte DNA fingerprinting conducted mid-way through year seven confirmed that, with one exception, ryegrass populations remained true-to-type in the cultivars sown with novel endophyte strains. The cultivar effect on DM yield was statistically significant in all measurement periods. Differences in yields among cultivars in years seven and eight were significantly and positively correlated with yield differences in years one to three ( $\mathrm{r}=0.685$ to 0.831 depending on which year contrasts were used). Thus, high-performing cultivars in the early years of the trial were also generally highperforming cultivars in years seven and eight, and vice-versa, indicating a high degree of yield stability in perennial ryegrass cultivars. Yield differences did not appear to be related to differences in cultivar heading date, ploidy, endophyte status, or genetic background. The relationship between yield in year ten and yields in years one to three was much weaker $(r=0.392)$ than the relationship in years seven and eight. Possible reasons for this are discussed.
\end{abstract}

Keywords: Perennial ryegrass; traits; persistence

\section{Introduction}

Three primary traits of grasses and clovers drive pasture productivity in New Zealand sheep, beef and dairy farm systems: dry matter (DM) yield, nutritive value, and persistence (defined as the stability, or persistence, of DM yield, after Parsons et al. (2011)).
Recent initiatives to develop economically-based ranking indices for perennial ryegrass cultivars in Ireland (Pasture Profit Index, PPI; McEvoy et al. 2011) and New Zealand (Forage Value Index, FVI; Bryant et al. 2012; Chapman et al. 2012) take these traits into consideration: the PPI includes all three, whereas the FVI currently includes only DM yield with the other traits being added progressively.

The PPI and FVI are evaluation tools, which require phenotypic data that represent the relative genetic merit of each cultivar. In New Zealand, such data are available for DM yield from the National Forage Variety Trial (NFVT) programme operated by the New Zealand Plant Breeders Research Association (NZPBRA) (e.g., Easton et al. 2001). Yield is measured for 3 years in each trial. Nutritive value information has not been collected systematically for ryegrass cultivars in New Zealand, whereas European forage plant evaluation systems routinely measure DM digestibility (e.g., Grogan \& Gilliland 2011).

By contrast, persistence is a more difficult trait to include in evaluation indices. Recent reviews have helped clarify how the trait should be defined and measured (Parsons et al. 2011), and documented the economic principles and some approaches for calculating the economic value of persistence (Malcolm et al. 2014; Ludemann et al. 2015). The challenge for the evaluation indices is to tease out the plant genetic component of persistence from among a host of other factors including variation in soil and climatic conditions, grazing and pasture management practices, damage from pests and diseases, ryegrass endophyte strain, and the interactions among them.

Our ability to determine how much variation exists among New Zealand perennial ryegrass cultivars for this important trait is restricted by the absence of long-term data comparing the persistence of yield of different ryegrass functional types. This paper reports an analysis of one such data set from a trial conducted under grazing in a summer-dry environment. The analysis tested the hypothesis that differences among cultivars in DM yield in the early years of pasture life 
are a useful predictor of long-term cultivar differences. Camlin \& Stewart (1976) noted that it is not practically or economically feasible to measure the yields of all cultivars for extended periods, therefore some means of predicting long-term yield is required. Testing for relationships between yields in the first few years postsowing and long-term yields is a logical place to start, since there is an abundance of yield data for cultivars up to 3 years post-sowing which may already contain information that can be used to estimate performance values for persistence.

\section{Materials and Methods Site details}

The trial was established on a gently sloping (gradient approximately 0.05:1) site at the Poukawa Research Station, central Hawke's Bay, in April 2005. Mean total annual rainfall at the site (measured from 1990 to 2014) is $757 \mathrm{~mm}$. Mean monthly rainfall falls in the range 50 to $70 \mathrm{~mm}$ for all months apart from July (106 $\mathrm{mm}$; Figure 1). Warm temperatures and high sunshine hours in summer lead to high evapotranspiration rates and frequent occurrence of summer/autumn droughts. The soil at the site is a relatively poorly drained Okawa silty loam with a potential rooting depth of 60 to $80 \mathrm{~cm}$ above a clay pan. Prior to establishment, the trial area was in old pasture, which was fully cultivated before sowing.

\section{Trial design and treatments}

Four blocks were laid out sequentially down-slope, with a $2 \mathrm{~m}$ wide buffer between each block. Each block consisted of two rows. Twenty-five perennial ryegrass cultivar $\times$ endophyte combinations were then randomly allocated to plots within blocks in two sub-groups: 19 diploid entries in one sub-group and 6 tetraploids in another sub-group. Tetraploids were separated from diploids to allow differential control of grazing if required. Plots were $2.4 \mathrm{~m}$ wide by $5.65 \mathrm{~m}$ long.

The 25 cultivar $\times$ endophyte combinations are listed in Table 1 , in order of heading date from early to very late. Three cultivars were included with two different endophytes: 'Bronsyn' (standard endophyte (SE) and AR1), 'Extreme' (AR1 and AR6), and 'Quartet' (SE and AR1). Henceforth, all entries are simply referred to as "cultivars". Details of the breeding history of all of the cultivars can be found in Stewart (2006). 'Ruanui' (released in the 1960s) and 'Nui' (1970s) were the oldest entries in the trial: all other cultivars were released in the 1990s and 2000s. Each cultivar was sown as a monoculture, at a sowing rate of $20 \mathrm{~kg}$ seed/ ha for diploids and $28 \mathrm{~kg} / \mathrm{ha}$ for tetraploids.

\section{Pasture measurements and management}

Dry matter yield was assessed continuously for the first

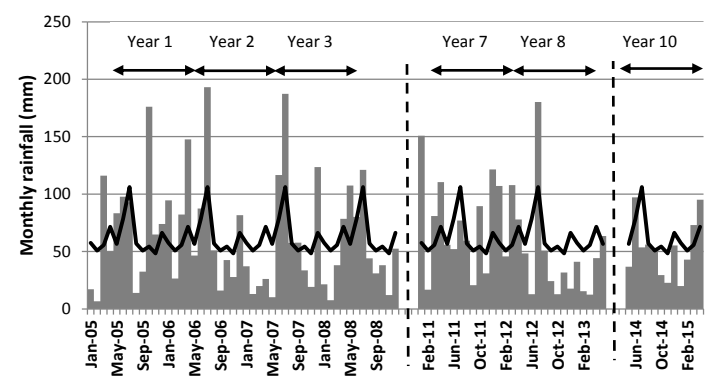

Figure 1 Monthly rainfall (bars) recorded at Poukawa in 2005-2008 (years one to three after sowing), 2011-13 (years seven and eight) and 2014/15 (year ten) compared with mean monthly rainfall 1990-2014 (solid line).

3 years after sowing. Measurements then ceased, but resumed from May 2011 to June 2013 (years seven and eight post-sowing). No yield data were collected in year nine, but measurements resumed from 1 May 2014 until 30 April 2015 (year ten post-sowing). In total, DM yield was measured on 42 occasions: 11 in year one, six in year two, seven in years three and seven, six in year eight, and five in year ten.

Dry matter yield was measured in a similar manner to that prescribed in NFVT protocols (NZPBRA 2010). One $0.46 \mathrm{~m}$ wide strip was cut from the length of each plot to a height of $30-40 \mathrm{~mm}$ above ground level when one or more entries reached a mean mass of approximately $2500 \mathrm{~kg} \mathrm{DM} / \mathrm{ha}$. Thus, $19 \%$ of the plot area was harvested at each sampling. The harvested areas moved sequentially across each plot so that the cut areas were re-visited at approximately every sixth sampling. A sub-sample of cut herbage was collected for each plot, then dried and weighed to determine DM content and yield. A further sub-sample of herbage harvested on 11 July 2011 and 12 January 2012 was retained and dissected by hand into perennial ryegrass, other grasses, broadleaf weeds, legumes, and dead matter to estimate pasture botanical composition.

After each DM yield measurement, all plots were grazed by ewes for up to 24 hours until grazing height reached $30-40 \mathrm{~mm}$ on some plots. Animals were then removed from the trial, and the entire area was trimmed to a consistent height of 30-40 mm. After each grazing, nitrogen $(\mathrm{N})$ was applied as urea $(46: 0: 0: 0 \mathrm{~N}: \mathrm{P}: \mathrm{K}: \mathrm{S})$ at a rate equivalent to $3-5 \%$ of mean trial yield. Potassic superphosphate ( $0: 6.3: 15.0: 7.7)$ was applied after every second grazing at a rate equivalent to $150 \mathrm{~kg} / \mathrm{ha}$.

\section{Endophyte genotyping}

Endophyte single sequence repeat (SSR) markers were used to estimate the genetic integrity of the sown populations mid-way through year seven post-sowing. Recruitment of volunteer ryegrass plants from the soil 
seed bank present when the experiment was sown was the most likely source of contamination of the sown populations. Ryegrass plants from old pastures throughout New Zealand are naturally infected with SE which has a different DNA fingerprint from the "novel" endophytes AR1, AR6 and NEA2. Therefore endophyte genotyping was restricted to the 16 cultivar entries sown with the novel endophytes to allow discrimination between volunteers and plants which were true to type for the sown cultivar (Table 1).

In November 2011, 90 tillers (22 or 23 per replicate) of these 16 cultivars were excised basally to ensure that endophyte in planta in the leaf sheath region was captured. Plant and endophyte DNA was isolated using the Extract-N-Amp Plant PCR Kit (Sigma, St Louis, MO, USA), as per the manufacturers' instructions. All DNA extracts were assayed using the endophyte SSR marker B 11 (Moon et al. 1999). B11 discriminates

Table 1 Mean total annual yields for 25 perennial ryegrass cultivars relative to the mean of all cultivars in years one to three inclusive, years seven and eight, and year ten after sowing. $(T)$ denotes tetraploid cultivars. Horizontal lines separate cultivars classified as early heading (-8 days or earlier), mid-season ( -7 to +7 days), late season ( +8 to +21 days) or very late heading (22 days or greater) (NZPBRA 2010).

\begin{tabular}{|c|c|c|c|c|c|c|}
\hline \multirow{3}{*}{$\begin{array}{l}\text { Cultivar } \\
\text { Meridian AR1 }\end{array}$} & \multirow{3}{*}{$\begin{array}{c}\begin{array}{c}\text { Heading } \\
\text { date } \\
\text { (days) }\end{array} \\
-17\end{array}$} & \multicolumn{5}{|c|}{ Yield relative to trial mean $(=100)$} \\
\hline & & \multicolumn{2}{|c|}{$\begin{array}{c}\text { Years } 1 \text { to } 3 \\
2005 / 06-2007 / 08\end{array}$} & $\begin{array}{c}\text { Years } 7 \text { and } 8 \\
2011 / 12-2012 / 13\end{array}$ & \multicolumn{2}{|c|}{$\begin{array}{l}\text { Year } 10 \\
2014 / 15\end{array}$} \\
\hline & & 101 & eh & 97 bf & 111 & $f$ \\
\hline Kingston SE & -3 & 105 & $\mathrm{hl}$ & $107 \mathrm{gh}$ & 107 & df \\
\hline Cannon AR1 & -1 & 92 & $\mathrm{bc}$ & $96 \mathrm{bd}$ & 101 & cf \\
\hline Ruanui NE & 0 & 94 & bd & 94 ac & 102 & cf \\
\hline Bronsyn SE & 0 & 108 & $\mathrm{~km}$ & $102 \mathrm{cg}$ & 104 & df \\
\hline Bronsyn AR1 & 0 & 106 & im & $103 \mathrm{dg}$ & 99 & $\mathrm{ce}$ \\
\hline Canterbury SE * & 0 & 87 & a & $90 \mathrm{ab}$ & 92 & ac \\
\hline Extreme AR1 & 0 & 101 & eg & $105 \mathrm{fh}$ & 106 & $\mathrm{df}$ \\
\hline Extreme AR6 & 0 & 106 & $\mathrm{jm}$ & $104 \mathrm{dh}$ & 107 & ef \\
\hline Super Nui SE & 0 & 101 & eh & $103 \mathrm{dg}$ & 102 & cf \\
\hline Commando AR1 & 1 & 98 & de & 97 be & 107 & ef \\
\hline Aries HD AR1 & 2 & 95 & $\mathrm{bd}$ & $101 \mathrm{cg}$ & 96 & be \\
\hline Horizon SE (T) & 2 & 101 & ei & 105 eh & 96 & $\mathrm{bc}$ \\
\hline Samson AR1 & 3 & 102 & $\mathrm{fj}$ & $101 \mathrm{cg}$ & 106 & $d f$ \\
\hline Hillary AR1 & 4 & 96 & $\mathrm{~cd}$ & 98 bf & 105 & $\mathrm{df}$ \\
\hline Aberdart AR1 & 15 & 97 & de & 106 fh & 100 & cf \\
\hline Supreme AR1 & 15 & 98 & $d f$ & $97 \mathrm{bf}$ & 106 & $d f$ \\
\hline Revolution AR1 & 19 & 103 & gj & 105 fh & 106 & $\mathrm{df}$ \\
\hline Banquet SE (T) & 21 & 109 & $\mathrm{Im}$ & 105 fh & 93 & $\mathrm{ac}$ \\
\hline Impact AR1 & 21 & 109 & Im & $112 \mathrm{~h}$ & 98 & $\mathrm{ce}$ \\
\hline Matrix SE & 23 & 104 & gk & $103 \mathrm{dg}$ & 106 & $\mathrm{df}$ \\
\hline Bealey NEA2 (T) & 25 & 110 & $\mathrm{~m}$ & $108 \mathrm{gh}$ & 95 & $\mathrm{bd}$ \\
\hline Quartet SE (T) & 25 & 94 & $\mathrm{bd}$ & $87 \mathrm{a}$ & 86 & $a b$ \\
\hline Quartet AR1 (T) & 25 & 91 & $a b$ & 86 a & 86 & $a b$ \\
\hline Sterling AR1 (T) & 25 & 91 & $a b$ & $86 \mathrm{a}$ & 83 & $a$ \\
\hline Mean & & 108 & 350 & 9025 & & 35 \\
\hline $\mathbf{P}$ & & $<0$. & 001 & $<0.001$ & $<0$ & 001 \\
\hline LSD & & 6 & 5 & 8.3 & & .2 \\
\hline
\end{tabular}

Means with a common letter are not significantly different. Endophyte strain is indicated after the cultivar name: NE = nil endophyte; SE = standard endophyte; AR1, AR6 and NEA2 = novel endophytes. * 'Canterbury' is an uncertified ecotype. 
between the endophyte strains AR1, AR6 and SE. The NEA endophyte is comprised of at least two discrete strains therefore a second SSR marker, ans025 (Simpson et al. 2012), was used to discriminate between NEA2 and the other endophytes. The SSR genotyping assays were conducted as described by Card et al. (2014). The proportion of tillers infected with the expected (inoculated) endophyte and with off-type (non-inoculated) endophytes within each population was estimated using $95 \%$ binomial confidence intervals.

\section{Statistical analysis}

The effect of cultivar on total annual yield was analysed using mixed models with treatment as a fixed effect and replicate, row within replicate and column as random effects. Row and column were included as random effects to account for the separation of the tetraploid cultivar sub-group in the plot layout. These terms were fitted using REML in GenStat 16.2. The procedure VMCOMPARISON in GenStat was used to make multiple comparisons using Fisher's protected lsd when the overall $\mathrm{F}$ test was significant. The correlation between yields in the different measurement periods (year 1, 2 and 3; years 7 and 8; and year 10) was also tested using regression analysis of the cultivar means in GenStat 16.2.

\section{Results}

\section{Climate}

Conditions following the sowing of the trial in April 2005 were generally favourable for germination and pasture establishment. Rainfall in May, June and July was slightly above the long-term average, August and September were relatively dry, and rainfall from October 2005 to May 2006 was 54\% above the long term average (Figure 1). Long, dry periods were experienced in 3 of the 6 years in which measurements were conducted: in year two from January to May 2007 ( 5 month total rainfall of $106 \mathrm{~mm}=36 \%$ of the long term average), in year eight from September 2012 to April 2013 (8 months, $200 \mathrm{~mm}=44 \%$ of long-term average rainfall), and in year ten from September 2014 to March 2015 ( 7 months, $155 \mathrm{~mm}=40 \%$ of the longterm average) (Figure 1).

\section{Botanical composition}

In July 2011, 6 years post-sowing, pastures were dominated by perennial ryegrass (mean across all cultivars $=87 \%$ of total harvested DM), with small contributions from broadleaf weeds and dead matter (mean $6 \%$ and $5 \%$ of total DM respectively). Botanical composition trends were similar in January 2012, although the contribution of broadleaf weeds was higher than in July 2011 (mean 20\% of DM). Perennial ryegrass comprised $74 \%$ of total DM at the January sampling.

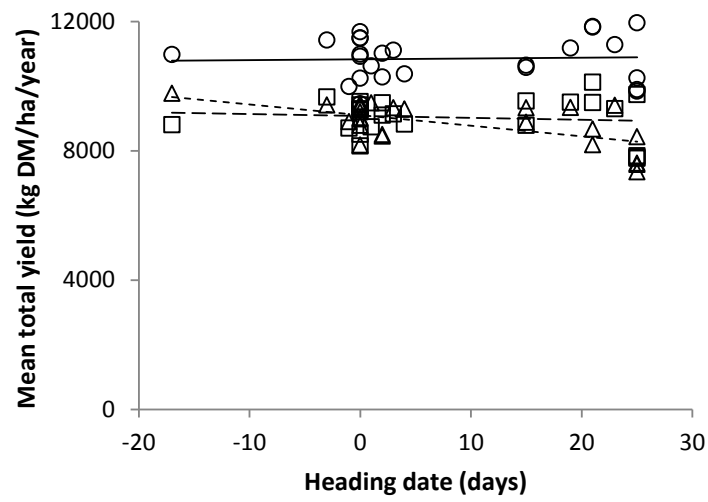

Figure 2 Relationship between cultivar heading date and mean total annual yields for years one to three inclusive $(0,-)$, years seven and eight $(\square,--)$, and year ten $(\Delta,---)$ after sowing.

\section{Endophyte genotyping}

The percentage of tillers collected in November 2011 that were infected with the expected (inoculated) endophyte strain fell within the range $84 \%$ to $99 \%$ for all but one of the 16 cultivars that were analysed. The exception was 'Canon' AR1: only $64 \%$ of tillers were infected with AR1 in this cultivar, while the rest were either endophyte-free (26\%) or infected with SE $(10 \%)$.

\section{DM yields and correlations}

Mean total annual DM yields ranged between $16.0 \mathrm{t}$ $\mathrm{DM} / \mathrm{ha}$ in year one to $6.5 \mathrm{t} \mathrm{DM} / \mathrm{ha}$ in year eight. The cultivar effect was statistically significant $(\mathrm{P}<0.001)$ in all years. Relative mean total annual yields for years one to three inclusive, years seven and eight, and year ten are shown in Table 1. The difference between the top-ranked and bottom-ranked cultivar in mean total annual yield was in the range 2250 to $2500 \mathrm{~kg} \mathrm{DM} / \mathrm{ha}$ for all three measurement periods.

Diploid and tetraploid cultivars featured among the highest performing entries relative to the trial mean in years one to three, and in years seven and eight, as did cultivars sown with standard endophyte and AR1. The tetraploids 'Bealey' NEA2 and 'Banquet' SE were relatively strong performers over this period but fell sharply in the yield rankings in year ten. 'Quartet' SE, 'Quartet' AR1 and 'Sterling' AR1 (all tetraploids) were consistently at the bottom of the yield rankings. There was no relationship between heading date and mean total annual yield in years one to three and years seven and eight (Figure 2), however a significant negative relationship was observed in year ten $(\mathrm{P}<0.01, \mathrm{y}=$ $9105-33.0 x, r=0.595)$.

The relationships between mean yields in years seven and eight, and yields in years one to three, were statistically significant in all cases $(\mathrm{P}<0.001$, 


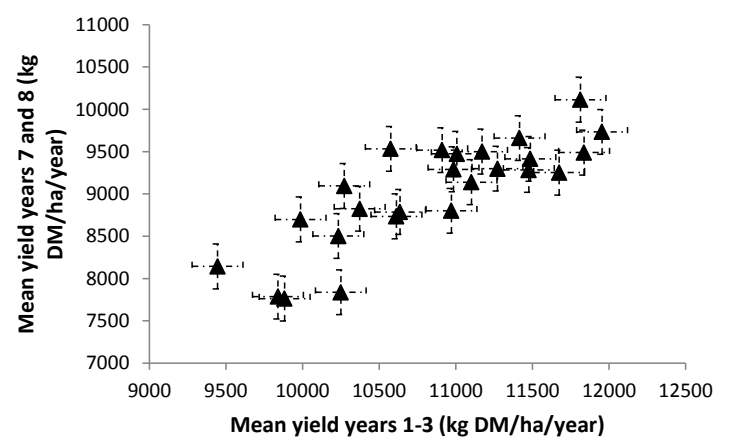

Figure 3 Mean total annual DM yield ( \pm s.e.m.) for years one to three versus years seven and eight for individual cultivars.

correlation coefficients shown in Table 2). The strongest relationship was between mean yields in years one to three and mean yields in years seven and eight (Table 2, Figure 3): $69 \%$ of the variation in yield in the later years was explained by variation in yield in the first three years.

However, the relationships between yield in year ten and yields in years one to three were weak. The regression was statistically significant for year ten versus year three $(\mathrm{P}<0.05)$, and approached significance for year ten versus the mean of years one to three $(\mathrm{P}=0.053)$ but only $15-23 \%$ of the variation in yield among cultivars in year ten was explained by variation in yield in the first three years. Correlation co-efficients for the relationships between yield in year ten and yields in years seven and eight were also low (Table 2).

\section{Discussion}

\section{Environmental conditions and plant survival}

Perennial ryegrass is well adapted to moist, cooltemperate conditions but is generally considered to

Table 2 Correlation matrix for the relationships between mean total annual dry matter yields in years seven, eight and ten, and in years one to three. The significance of the regression is indicated alongside each coefficient.

\begin{tabular}{|c|c|c|c|c|}
\hline DM year 7 & 1.000 & & & \\
\hline DM year 8 & $0.745^{* *}$ & 1.000 & & \\
\hline DM years 7 and 8 & $0.953^{* *}$ & $0.907^{* * *}$ & 1.000 & \\
\hline DM year 10 & $0.538^{* *}$ & $0.487^{*}$ & $0.525^{* *}$ & 1.000 \\
\hline DM year 3 & $0.772^{* *}$ & $0.732^{* * *}$ & 0.811 & $0.475^{*}$ \\
\hline \multirow[t]{2}{*}{ DM years 1 to 3} & $0.818^{* * *}$ & $0.685^{* * *}$ & $0.831^{* * *}$ & 0.392 NS \\
\hline & $\begin{array}{c}\text { DM } \\
\text { year } 7\end{array}$ & $\begin{array}{c}\text { DM } \\
\text { year } 8\end{array}$ & $\begin{array}{c}\text { DM } \\
\text { years } \\
7 \text { and } 8\end{array}$ & $\begin{array}{c}\text { DM } \\
\text { year } 10\end{array}$ \\
\hline
\end{tabular}

be moderately to poorly tolerant of prolonged periods of low soil moisture availability (Levy 1970). The summer-dry environment in which this experiment was conducted was therefore a challenging one for ryegrass growth and survival. Despite this, swards were dominated by perennial ryegrass in July 2011, 6 years post-sowing. Endophyte marker analysis of survivor plants collected 4 months later clearly showed strong survival of the sown ryegrass genotypes, confirming that the ryegrass populations remained true-to-type over this period of time.

High genetic integrity of the sown cultivars is a necessary condition for testing the hypothesis since significant ingress of other perennial ryegrass germplasm into the sown populations would have confounded the analysis of genetic differences. Apart from one cultivar ('Cannon' AR1), the frequency of SE infection ranged between 0 and 5\%. Between 1 and $10 \%$ of plants contained no endophyte but, otherwise, between 84 and $99 \%$ of plants in populations sown with novel endophytes were infected with the strain that they were sown with. Because the analysis was restricted to cultivars sown with novel endophytes, we cannot be certain that the cultivars sown with SE also retained a high proportion of plants that were true-totype, but it is reasonable to expect that this was the case.

\section{Genetic variation in yield}

The experiment reported here compared a wide range of perennial ryegrass functional types (diploids and tetraploids; early to very late maturity dates) and genetic backgrounds (including New Zealand and Australian ecotypes; southern and northern European material; and some cultivars including Italian ryegrass and meadow fescue parentage). Many were based on the old Hawke's Bay and Mangere ecotypes that have been widely used in perennial ryegrass breeding programmes for many decades (Stewart 2006), and will continue to be used because of their strong adaptation to New Zealand conditions (Easton et al. 2011).

All cultivars established well in the first year (2005/06) to produce between 14.0 and $17.3 \mathrm{t} \mathrm{DM} / \mathrm{ha}$, indicating ample opportunity for all entries to express their yield potential and survival ability in subsequent years. Thereafter, in general, the best-performing cultivars yielded about $10 \%$ more than the mean of all cultivars (Table 1). This aligns well with Easton et al. (2001) who also reported a $10 \%$ advantage to the highest yielders compared with the mean yield in their analysis of 17 NFVT trials from throughout New Zealand. Easton et al. (2001) also noted that, because of the high variability between sites and years, cultivar performance can only truly be judged from the results of several trials. Hence, we draw no conclusions about 
which were the "best" and which were the "poorest" cultivars from the present trial. Rather we simply highlight that there was a significant effect of cultivar on yield in years one to three, another condition which must be met in order to test the hypothesis.

No clear patterns related to endophyte strain or ploidy could be discerned from the DM yield data for years one to three, and years seven and eight (Table 1). For example, while three tetraploid cultivars ('Quartet' AR1, 'Quartet' SE and 'Sterling' SE) were low-performing throughout (and so did not establish a yield advantage relative to the control cultivar 'Ruanui' at any stage), other tetraploids (notably 'Bealey' NEA2 and 'Banquet' SE) were consistently among the highest yielding cultivars in years one to three and seven and eight. Similarly, there was no significant relationship between heading date and total annual DM yield in years one to three and seven and eight (Figure 2), although the relationship was significant in year ten. This observation is discussed further in the following section.

\section{Persistence of yield differences}

The hypothesis that yield differences among cultivars in the early stages of pasture life are a useful predictor of long-term yield differences was supported by the statistically significant relationships shown in Table 2. The most robust relationship was based on the average yields of years one to three and the average yields of years seven and eight (Figure 3): nearly $70 \%$ of the variation in the latter was explained by variation in yield in former, indicating that high-performing cultivars in the early years generally remained high performers in years seven and eight, and vice-versa. Correlations between single years were significant up to and including year eight (for example, the correlation co-efficient for the relationship between yield in year three and yield in year seven was 0.772 , Table 2), but the average yields offered better predictive ability. Easton et al. (2001) analysed yield data from 17 NFVT trials and noted that yield in year three was positively correlated with yield in year one (coefficients were not reported in the paper). Farmers expect new pastures to perform strongly for much longer than this, therefore 3 years' data is insufficient to determine whether or not the yield advantage of the higher-performing cultivars meets those expectations. The results of the present analysis confirm that, at least for the conditions under which this trial was conducted, perennial ryegrass cultivars are genetically stable for yield persistence up to 8 years post-sowing.

However, the relationship between yield in year ten and yields in years one to three was much weaker (Table 2), raising doubts about how much confidence can be placed in initial yield differences to predict yield beyond 8 years. This could be the result of an interaction between year and ryegrass functional types. Total rainfall from September 2014 to March 2015 (155 mm, Figure 1) was only $40 \%$ of the longterm average. The onset of dry conditions from early spring may have favoured early and mid-season flowering cultivars relative to late and very late flowering cultivars, many of which were among the highest yielders in years seven and eight (Table 1). The emergence of a statistically significant relationship between heading date and yield in year ten (Figure 2) supports this explanation, but this must be treated with caution because the relationship is strongly influenced by the single early-maturing cultivar ('Meridian') that was included in the trial.

When the regression was restricted to just the early and mid-maturing cultivars, correlation coefficients increased (data not presented) but, still, only $22-24 \%$ of the variation in yield of the early and mid-maturing cultivars in year ten was explained by yields in years one to three. Also, very similar rainfall patterns were experienced in year eight (total annual rainfall from September 2012 to April $2013=200 \mathrm{~mm}, 44 \%$ of the long-term average; Figure 1), yet the corresponding relationships were highly significant (Table 2) and explained around $50 \%$ of the variation in yield in year eight.

An alternative explanation is that somewhere around years eight to ten after sowing, cultivars began to separate according to genetic differences in their ability to sustain their relative yield position. The cultivars that fell substantially in their relative ranking between years seven and eight and year ten are of particular interest here because if there are common features among them, this may point to plant characteristics that are negatively associated with long-term persistence. Four cultivars can be included in this group: 'Horizon' SE, 'Banquet' SE, 'Impact' AR1 and 'Bealey' NEA2 (Table 1). Of these, 'Horizon', 'Banquet' and 'Bealey' are tetraploids and 'Impact' is classified as a diploid hybrid cultivar although it was bred from perennial ryegrass germplasm.

Pastures based on older tetraploids typically have lower tiller density than pastures based on diploids (e.g., Tozer et al. 2014). This may limit their ability to recover from periods of moisture stress because there is a positive relationship between tiller density of the pasture entering the stress period and the rate and extent of the recovery after the stress is alleviated (Barker et al. 1985). However, apart from Sugiyama \& Nikara (2004) who observed that tiller mortality was greater in tetraploid than diploid perennial ryegrasses under a severe moisture deficit, there is little evidence 
from controlled studies to indicate that tetraploids differ from diploids in their physical survival of, or recovery from, growth stresses.

More information on yield and ryegrass population characteristics is currently being collected from the trial to help identify factors that may be involved in the apparent change between years seven and eight and year ten, and their implications for assessing genetic differences in yield persistence.

\section{Conclusions}

There are shortcomings in the data set used for this analysis. For example, it comes from only one trial in one location, yield was not measured continuously across all ten years, insect pest populations were not monitored, and the endophyte infection frequency of the original seed lines is not known. Nonetheless, it contains information on a wide range of different perennial ryegrass functional types and breeding backgrounds grown in an environment characterised by frequent, prolonged drought conditions which pose a stern challenge to perennial ryegrass survival.

High-yielding cultivars in the first 3 years of the trial were also, generally, high yielders 7 to 8 years post-sowing, indicating a high degree of yield stability in perennial ryegrass cultivars. Yield data from standard evaluation trials such as those conducted in the NFVT programme could, therefore, also be used to rank cultivars for longer-term yield (persistence) in economically-based indices such as the DairyNZ Forage Value Index, at least as an interim approach until more-direct information is available. However, more information is needed to help explain the poorer relationship between yields in years one to three and yield in year ten observed here. Long-term data from other environments are also needed to establish whether or not the stability of yield of ryegrass cultivars seen here holds in other situations, for example in the northern North Island where insect pest pressure and endophyte interactions are more important factors in pasture persistence.

\section{ACKNOWLEDGMENTS}

A large number of On-Farm Research staff were involved in the setting up and running of this trial, but particular thanks go to Mike Slay, Noel Smith, Kay Ward and Regan Smith. Collection of yield data in years seven, eight and ten of the trial was supported by funding from New Zealand dairy farmers through DairyNZ Inc. (projects SY705 and RD1404). Technical assistance with the endophyte genotyping from Won Hong, AgResearch, and statistical advice and analysis from Barbara Dow, DairyNZ, is gratefully acknowledged.

\section{REFERENCES}

Barker, D.J.; Chu, A.C.P.; Korte, C.J. 1985. Some effects of spring defoliation and drought on perennial ryegrass swards. Proceedings of the New Zealand Grassland Association 46: 57-63.

Bryant, J.; Chapman, D.; McMillan, W.; Thorrold, B.; Willocks, M.; Green, D.; Kerr, G.; Judson, G.; Cookson, T.; Edwards, G. 2012. Valuing the forage you grow: Economic indices for pasture cultivars. pp 28-34. In: Proceedings of the South Island Dairy Event, June 2012.

Camlin, M.S.; Stewart, R.H. 1976. The assessment of persistence and its application to the evaluation of early perennial ryegrass cultivars. Journal of the British Grassland Society 31: 1-6.

Card, S.D.; Faville, M.J.; Simpson, W.R.; Johnson, R.D.; Voisey, C.R.; De Bonth, A.C.M.; Hume, D.E. 2014. Mutualistic fungal endophytes in the Triticeae - survey and description. FEMS Microbiology Ecology 88: 94-106.

Chapman, D.; Bryant, J.; McMillan, W.; Thorrold, B.; Willocks, M.; Green, D.; Kerr, G.; Judson, G.; Cookson, T.; Edwards, G. 2012. An economic forage value index for New Zealand dairy farmers. pp 422423. In: Proceedings of the 5th Australasian Dairy Science Symposium.

Easton, H.S.; Baird, D.B.; Cameron, N.E.; Kerr, G.A.; Norriss, M.; Stewart, A.V. 2001. Perennial ryegrass cultivars: herbage yield in multi-site plot trials. Proceedings of the New Zealand Grassland Association 63: 183-188.

Easton, H.S.; Stewart, A.V.; Kerr, G.A. 2011. Ryegrass in pastures - breeding for reslience. Pasture Persistence. Grassland Research and Practice Series 15: 139-147.

Grogan, D.; Gilliland, T.J. 2011. A review of perennial ryegrass evaluation in Ireland. Irish Journal of Agricultural and Food Research 50: 65-81.

Levy, E.B. 1970. Grasslands of New Zealand. Third edition. A.R. Shearer, Government Printer, Wellington. 374 pp.

Ludemann, C.L.; Jacobs, J.L.; Smith, K.F. 2015. The economic significance of maintaining pasture production at its peak value. Crop and Pasture Science 66: 205-213.

Malcolm, B.; Smith, K.F.; Jacobs, J.L. 2014. Perennial pasture persistence: the economic perspective. Crop and Pasture Science 65: 713-720.

McEvoy, M.; O'Donovan, M.; Shalloo, L. 2011. Development and application of an economic ranking index for perennial ryegrass cultivars. Journal of Dairy Science 94: 1627-1639.

Moon, C.D.; Tapper, B.A.: Scott, B. 1999. Identification of Epichloë endophytes in planta by a microsatellite- 
based PCR fingerprinting assay with automated analysis. Applied and Environmental Microbiology 65: 1268-1279.

New Zealand Plant Breeding and Research Organisation (NZPBRA). 2010. National Forage Variety Trials (NFVT) - Trial Protocol July 2010.

Parsons, A.J.; Edwards, G.R.; Newton, P.C.D.; Chapman, D.F.; Caradus, J.R.; Rasmussen, S.; Rowarth, J.S. 2011. Past lessons and future prospects: plant breeding for yield and persistence in cool-temperate pastures. Grass and Forage Science 66: 153-172.

Simpson, W.R.; Schmid, J.; Singh, J.; Faville, M.J.; Johnson, R.D. 2012. A morphological change in the fungal symbiont Neotyphodium lolii induces dwarfing in its host plant Lolium perenne. Fungal Biology 116: 234-240.
Stewart, A.V. 2006. Genetic origins of perennial ryegrass (Lolium perenne) for New Zealand pastures. pp. 11-20. In: Proceedings of the 13th Australasian Plant Breeding Conference.

Sugiyama, S.: Nikara, C. 2004. Differential contribution of avoidance and tolerance to dehydration resistance in populations of perennial ryegrass, Lolium perenne L. Australian Journal of Agricultural Research 55: 33-37.

Tozer, K.N.; Chapman, D.F.; Bell, N.L.; Crush, J.R.; King, W.M.; Rennie, G.M.; Wilson, D.J.; Mapp, N.R;, Rossi, L.; Aalders, L.T.; Cameron, C.A. 2014. A botanical survey of perennial ryegrass-based dairy pastures in three regions of New Zealand: implications for ryegrass persistence. New Zealand Journal of Agricultural Research 57: 14-29. 